\title{
A Study on Knowledge and Skill Level of Public Speaking for Employment among UG and PG Students of Gbpuat Pantnagar, Uttarakhand, India
}

\author{
Smriti Singh* and Neha
}

Department of Agricultural Communication, GBPUA\&T, Pantnagar, India

*Corresponding author

\section{A B S T R A C T}

'Public speaking is speaking to a group of people in a structured, deliberate manner intended to inform, influence, or entertain the listeners' (Wikipedia). Therefore, a good speech should be substantial and engaging. There are three main points which the most orators should concern for making a good public speaking including preparation, body

\begin{tabular}{|l|}
\hline Ke y w or d s \\
Capacity building, \\
Knowledge, Skill, \\
Training \\
\hline Article Info \\
\hline Accepted: \\
04 June 2019 \\
Available Online: \\
10 July 2019 \\
\hline \hline
\end{tabular}
languages, and speaking skills. A study has been undertaken during the month of May 2018 to assess the knowledge level and skill level regarding public speaking for employment among the students of GBPUA\&T, Pantnagar, and Uttarakhand. For this the knowledge test and skill test has been designed and administered to a sample of 20 respondents which were drawn through the stratified equal proportionate sampling technique from five colleges of university i.e. COA,COT, COF, Veterinary College and $\mathrm{COH}$ in which strata of UG and PG were made. The result of knowledge test revealed that 20 per cent respondents fall in the high scorer category, 60 per cent fall in the medium scorer category and 20 per cent fall in the low scorer category. The result of skill test depicted that 25 per cent respondents fall in high scorer category, 60 per cent fall in medium scorer category and 15 per cent fall in low scorer category. Students identified their training needs on using verbal skills effectively, concluding the speech, grabbing the attention of audience, boosting confidence and reducing anxieties as major areas of to be covered under training programme. The study recommends organizing capacity building trainings for enhancement of knowledge and skills of public speaking among students which will make them succeed in all aspects of their job life.

\section{Introduction}

Nothing in life is more important than ability to communicate effectively

Communication in its multiple forms pervades today's competitive environment. Public speaking is a process, an act and an art of making speech before an audience. The art of public speaking is not new. Its tradition can be traced back to Classical Greece (490-322BC).

Any young men leaving that time were expected to acquire and develop public speaking skills as part of their duties as citizens. The first rules of a public speech were elaborated on over 2000 years ago by Greek philosopher and teacher of Alexander the Great - Aristotle. The three basic parts of 
persuasion includes Ethos (credibility of the speaker), Logos (logic behind any conclusion drawn by a speaker) and Pathos (emotional appeal or ability to create connection between the speaker and his audience."

Public speaking is an act of presenting your thoughts in before an audience in order to inform, influence or entertain them.

Communication skills are critical for intellectual development, career trajectory, and civic engagement. In the category of "Intellectual and practical skills" public speaking is listed as one of these core skills (Rhodes, 2010, p. 10).

Good public speaking skills are an essential part of achieving career goals and increasing success in the workplace. Improving your public speaking skills also improves your interpersonal communication abilities. Being able to communicate your knowledge of a field, ideas, and objectives to co-workers, clients, management, and larger groups is necessary to complete projects and progress in your career overall. Public speaking is universally applicable to all types of majors and occupations and is seen as a critical employability skill for job seekers (RocklerGladen, 2009; U.S. Department of Labor, 2000). No matter what your ambitions and interests are, developing speaking skills will benefit your personal, professional, and public life.

Watzlawick, et al., (1967, cited in litsoil, 2012): public speaking is the ability to speak in public, in a coherent and in a planned with a specific purpose. Public speaker is the person who performs the public speaking. Some examples of professions who's the activity use public speaking at the work, namely: orator, speaker, presenter and motivator. Public speaking is also transactional in nature.

Morreale and Pearson (2008): The capability to communicate competently is essential for personal contentment, academic achievement, and professional career success.

Slagel (2009): Public speaking refers to the communication practice of a speaker sharing ideas with an audience primarily through the speech.

Schreiber (2011): stated that one important communicational task is giving an informative public speech, i.e., presenting content to an audience).

Hunt et al., (2014): stated that in the context of school and work, competent speakers are more successful in conveying their knowledge, ideas, and opinions. Further, being able to communicate competently can enhance relationships with peers, parents, and teachers

Ginkel et al., (2015), Mastering public speeches is acknowledged as a core competence for well-educated students and it has been integrated into the educational standards of several countries such as Germany (Kultusministerkonferenz, 2005) or the United States (Common Core State Standards Initiative, 2010). Working on your speaking skills enables you to polish your communication and leadership skills and increase confidence (areas that are key to career advancement).

Self-confidence is a key for taking on projects you might otherwise not handle. Another skill or strength that's helpful when advocating for yourself is the ability to think on your feet. You can practice this by organizing your thoughts within a short timeframe to respond to an impromptu question or topic. This way, when a colleague or your boss asks you a tough question, you will feel confident speaking off the cuff.

The study aims to study the background 
profile of UG and PG students of GBPUA\&T. To find out the level of knowledge possessed by the students of GBPUAT Pantnagar regarding public speaking.

To find out the skill level of GBPUAT Pantnagar students regarding public skill.

To identify the student's training needs for public speaking skills.

\section{Materials and Methods}

The study was conducted purposively on UG and PG students of GBPUA\&T Pantnagar in Uttarakhand. 10 students each from UG and PG level were randomly selected as respondents for the study. A total of 20 students constituted the sample for study. Data were obtained from primary sources with the aid of structured and unstructured knowledge test and skill test regarding public speaking.

Descriptive statistics and inferential statistical tools were used to analyze data.

\section{Knowledge test}

In this the respondents were asked to reply each and every question included in the knowledge test. One score was assigned to each correct answer and zero to incorrect or no answer in the knowledge test. As the total number of questions in the knowledge test was 16, the maximum obtainable knowledge scores was 16.The knowledge scores assigned to each respondent was some totaled and the mean knowledge score $\left({ }^{X}=11.7\right)$ and the standard deviation (S.D=2.40) were computed. Knowledge score was categorized into three levels i.e. 1) low, if the total score of an individual respondent was below $(<9.3), 2)$ medium, if the scores varied from (9.3-14.1) and 3) high, if individual score was above (>14.1) (Table 1).

\section{Measurement of skill}

To measure the level of public speaking skills of the respondent, 2 point rating scale with their scores i.e. skill known to them (1) and unknown to them (0). The overall scores of the respondents reflecting the level of skill was found out by taking the arithmetic mean of scores given to all 32 statements.

Finally the respondents were categorized into three groups i.e. High (>41.12), Medium $(31.58-41.12)$ and Low $(<31.58)$ on the basis of $\left({ }^{\bar{X}}=36.35\right)$ and S.D (4.77) (Table 2).

\section{Focused Group Discussion}

A focus group discussion is a structured discussion used to obtain in-depth information (qualitative data - insight) from a group of people about a particular topic. The purpose of a focus group is to collect information about people's opinions, beliefs, and attitudes, perceptions, not to come to consensus or make a decision.

A FGD was conducted with students to know the reasons behind less knowledge and skill score on a particular statement. It was performed to triangulate the date collected through structured schedule.

\section{Background characteristics of GBPUAT students}

\section{Gender}

A perusal of table 3 shows that 55 per cent of the respondents involved in our study were female and 45 per cent respondents were male.

\section{Habitat background}

Table 4 depicts that majority of students involved in our study belong to the rural background and 45 percent hail from an urban background. 
It appears from Table 5 that English was preferred as a mode of public speaking by majority of students' i.e. 55 percent, 30 percent respondents feel comfortable with both Hindi and English for public speaking and mere 15 per cent of students preferred Hindi language for public speaking. Table 6 shows that majority of students ( 75 per cent) had education from an English medium school and only 25 per cent of students had Hindias a medium of instruction in school. No respondent belonged to any other boards.

Majority of students want to have their career in academics as a scientist, professor, teacher etc and other governmental jobs (45 per cent) and 30 per cent of the respondents are attracted to the limelight of private agencies and 3 percent want to be in other profession like dancers, athlete etc. Only 2 per cent aspire to engage in entrepreneurial activities (Table 7).

\section{Computation of knowledge test}

A perusal of Table 8 reveals that 60 per cent of students had medium level of knowledge regarding Public speaking skills. One fifth (20 per cent) of students had higher knowledge level and low knowledge level regarding public speaking. It appears from Table 9 that 60 per cent of students had medium level of skill regarding Public speaking skills. 25 per cent of students had higher skill level and remaining 15 per cent had low skill level with respect to public speaking.

It appears from Table 10 that 60per cent of students had knowledge regarding the function of Public speaking i.e. to inform, to persuade $\&$ to entertain the audience. 40 percent had knowledge about the how ideas are generated during the brainstorming session. It was found through FGD that students have knowledge about function and brainstorming because a course is offered to them on Communication skills during their UG programme, 75 percent of students has skill to understand the audience centeredness.

Forty five percent students have knowledge about the speech moves around the interest and motive of the audience. Mainly secondary data are preferred for content preparation which includes books, journals and internet.50 per cent respondents knew about this method of data collection.

60 percent students know that it is effective to have right pace for delivery the message in public speaking. It enhances the credibility of the speaker. It was found during FGD that students know the pace because of the course at UG level. The speech is divided into 3 major components, are Introduction, Body and Conclusion. This fact is known by 50 percent of the students. The longest and most important part of the speech is body and 40 percent of the students have adequate knowledge about the content and size of the body because they have participated in different public speaking activities during their school and college time. Dressing etiquettes are essential as it represents the attitude \& emotions of the speaker towards a specific topic and it is important for public speaking, told by 45 percent of the students. It also attracts the attention of the audience as it should not be eye catching and revealing.35 percent students have knowledge about the pitch, volume, voice modulation are the verbal components of speech and eye contact and body language are the nonverbal verbal components of speech. 85 percent students responded that technicalities issues should be checked prior to public speaking. 
Table.1 Criteria to be used to distinguish students on the basis of different knowledge level

\begin{tabular}{|c|c|c|c|}
\hline $\begin{array}{c}\text { Knowledge test score } \\
\text { category }\end{array}$ & Criteria & Overall mean & SD \\
\cline { 1 - 2 } High scorers & Above $(\mathrm{X}+\mathrm{nD})$ & 11.7 & 2.40 \\
\hline Medium scorers & Between $(\mathrm{X}-\mathrm{SD})$ & \\
\cline { 1 - 2 } Low scorers & Below $(\mathrm{X}-\mathrm{SD})$ & \\
\hline
\end{tabular}

Table.2 Criteria to be used to distinguish students on the basis skill present $(n=20)$

\begin{tabular}{|c|c|c|c|}
\hline $\begin{array}{c}\text { Skill test score } \\
\text { category }\end{array}$ & Criteria & Overall mean & SD \\
\hline High scorers & Above $(\mathrm{X}+\mathrm{SD})$ & 36.35 & 4.77 \\
\hline Medium scorers & Between $(\mathrm{X}-\mathrm{SD})$ & \\
\cline { 1 - 2 } Low scorers & Below $(\mathrm{X}-\mathrm{SD})$ & \\
\hline
\end{tabular}

Table.3 Gender of GBPUAT students $(n=20)$

\begin{tabular}{|c|c|}
\hline Male & Female \\
\hline $\mathbf{9 ( 4 5 \% )}$ & $11(55 \%)$ \\
\hline
\end{tabular}

Table.4 Habitat background $(n=20)$

\begin{tabular}{|c|c} 
Rural Background & Urban Background \\
\hline $\mathbf{9}(\mathbf{4 5 \% )}$ & $11(55 \%)$ \\
\hline
\end{tabular}

Table.5 Language preferred for public speaking

\begin{tabular}{|c|c|c|}
\hline $\begin{array}{c}\text { Language preferred for public } \\
\text { speaking }\end{array}$ & Frequency & Percentage \\
\hline Hindi & 3 & 15 \\
\hline English & 11 & 55 \\
\hline Both & 6 & 30 \\
\hline
\end{tabular}

Table.6 Medium of school education $(n=20)$

\begin{tabular}{|c|c|c|}
\hline Medium of School education & Frequency & Percentage \\
\hline English & 15 & 75 \\
\hline Hindi & 5 & 25 \\
\hline Other & - & - \\
\hline
\end{tabular}


Table.7 Occupation aspired $(n=20)$

\begin{tabular}{|c|c|c|}
\hline Occupation Preferred & Frequency & Percentage (\%) \\
\hline Academicians (Scientist, Professor, Teacher etc) & 9 & 45 \\
\hline Private Agencies & 6 & 30 \\
\hline Entrepreneur & 2 & 10 \\
\hline Others & 3 & 15 \\
\hline
\end{tabular}

Table.8 Frequency distribution of respondents according to their level of knowledge about public speaking skills for employment

\begin{tabular}{|c|c|c|}
\hline Scorer of Knowledge Test & Frequency & Percentage (\%) \\
\hline High $(>14.1)$ & 4 & 20 \\
\hline Medium $(9.3-14.1)$ & 12 & 60 \\
\hline Low $(<9.3)$ & 4 & 20 \\
\hline
\end{tabular}

Table.9 Frequency distribution of respondents according to their skill score about skills needed for public speaking for employment

\begin{tabular}{|c|c|c|}
\hline Scorer of Skill Test & Frequency & Percentage (\%) \\
\hline High $(>\mathbf{4 1 . 1 2})$ & 5 & 25 \\
\hline Medium $(31.58-41.12)$ & 12 & 60 \\
\hline Low $(<31.58)$ & 3 & 15 \\
\hline
\end{tabular}

Table.10 Statement wise distribution of knowledge scores to students

\begin{tabular}{|c|c|c|}
\hline Questions (in short) & Frequency & Percentage $(\%)$ \\
\hline Function of Public speaking & 12 & 60 \\
\hline Process of idea generation in short time & 8 & 40 \\
\hline Audience centeredness & 9 & 45 \\
\hline Disposition of audience toward the topic & 10 & 50 \\
\hline Secondary sources referred for content preparation & 9 & 45 \\
\hline Pace of delivery & 12 & 60 \\
\hline Components of speech & 10 & 50 \\
\hline Longest \& important part of speech & 8 & 40 \\
\hline 9. Dressing etiquettes & 9 & 45 \\
\hline $\begin{array}{l}\text { 10. Effective non verbal components (pitch volume voice } \\
\text { modulation) }\end{array}$ & 5 & 25 \\
\hline 11. Verbal components under consideration & 4 & 20 \\
\hline Technical issues regarding public speaking & 13 & 65 \\
\hline Avoiding blunders & 13 & 65 \\
\hline Follow up strategies & 13 & 65 \\
\hline Positive body language & 7 & 35 \\
\hline Proscriptions in public speaking & 11 & 55 \\
\hline
\end{tabular}


Table.11 Statement wise distribution of students according to the skill test scores

\begin{tabular}{|c|c|c|}
\hline Questions (in short) & Frequency & Percentage $(\%)$ \\
\hline 17. Art of topic selection & 1 & 5 \\
\hline $\begin{array}{l}\text { 18. Purpose behind } \quad \text { speech } \\
\text { preparation }\end{array}$ & 13 & 65 \\
\hline 19. Identification of audience profile & 5 & 25 \\
\hline $\begin{array}{l}\text { 20. Analysing level of knowledge \& } \\
\text { attitude of audience }\end{array}$ & 10 & 50 \\
\hline 21. Content matter & 3 & 15 \\
\hline Methods of sorting out the content & 7 & 35 \\
\hline 23. Division of content of the speech & 12 & 60 \\
\hline $\begin{array}{l}\text { 24. Organisational pattern of the } \\
\text { speech }\end{array}$ & 9 & 45 \\
\hline $\begin{array}{l}\text { 25. Techniques of conversion of } \\
\text { complex things into simpler form }\end{array}$ & 7 & 35 \\
\hline $\begin{array}{l}\text { 26. Integration of } \\
\text { materials }\end{array}$ & 9 & 45 \\
\hline $\begin{array}{l}\text { 27. Concluding skills to have long } \\
\text { lasting impression }\end{array}$ & 6 & 30 \\
\hline 28. Degree of words use & 12 & 60 \\
\hline 29. Ideal pace & 2 & 10 \\
\hline 30. Dressing sense & 12 & 60 \\
\hline 16.Posture preferred to be maintained & 5 & 25 \\
\hline 17.Preferred facial expression & 10 & 50 \\
\hline 18.Preferred movement & 9 & 45 \\
\hline 19.Method of eye contact & 11 & 55 \\
\hline 20.Gesture preferred & 7 & 35 \\
\hline 21.Appropriate strategy & 6 & 30 \\
\hline 22.Indicators to know audience interest & 9 & 45 \\
\hline 23.Effective use of voice & 9 & 45 \\
\hline 24Defending skills(Q-A) & 12 & 60 \\
\hline 25.Strategy to conclude & 10 & 50 \\
\hline
\end{tabular}


Table.12 Distribution of students according to training needs for enhancement of public speaking skills

\begin{tabular}{|c|c|c|c|c|c|}
\hline $\begin{array}{c}\text { Statements of training } \\
\text { areas }\end{array}$ & Most Needed & Needed & $\begin{array}{l}\text { Least } \\
\text { Needed }\end{array}$ & $\begin{array}{l}\text { Weighted } \\
\text { Mean Score }\end{array}$ & Rank \\
\hline $\begin{array}{l}\text { 1. Gathering the data } \\
\text { from different secondary } \\
\text { sources }\end{array}$ & 9 & 10 & 1 & 2.4 & $\mathbf{V}$ \\
\hline $\begin{array}{l}\text { 2. Using the statistical } \\
\text { data to support the speech }\end{array}$ & 7 & 12 & 1 & 2.3 & VI \\
\hline $\begin{array}{l}\text { 3. Creating } \\
\text { transitions between } \\
\text { introduction, body and } \\
\text { conclusion }\end{array}$ & 12 & 6 & 2 & 2.5 & IV \\
\hline $\begin{array}{l}\text { 4. Using stories, } \\
\text { examples in the content }\end{array}$ & 8 & 10 & 2 & 2.4 & V \\
\hline $\begin{array}{l}\text { 5. Editing the content } \\
\text { before finalizing }\end{array}$ & 10 & 10 & & 2.5 & IV \\
\hline $\begin{array}{l}\text { 6. Aligning the } \\
\text { content with the audience }\end{array}$ & 11 & 7 & 2 & 2.4 & $\mathbf{V}$ \\
\hline 7. Starting the speech & 10 & 8 & 2 & 2.4 & V \\
\hline $\begin{array}{l}\text { 8. Grabbing the } \\
\text { attention of the audience }\end{array}$ & 14 & 4 & 2 & 2.6 & III \\
\hline $\begin{array}{l}\text { 9. Using verbal skills } \\
\text { effectively }\end{array}$ & 15 & 5 & & 2.75 & $\mathbf{I}$ \\
\hline $\begin{array}{l}\text { 10. Using non-verbal } \\
\text { skills effectively }\end{array}$ & 12 & 6 & 2 & 2.5 & IV \\
\hline $\begin{array}{l}\text { 11. Boosting } \\
\text { confidence and reducing } \\
\text { the anxieties }\end{array}$ & 14 & 5 & 1 & 2.6 & III \\
\hline $\begin{array}{l}\text { 12. Concluding the } \\
\text { speech }\end{array}$ & 14 & 6 & & 2.7 & II \\
\hline $\begin{array}{l}\text { 13. Responding the } \\
\text { audience }\end{array}$ & 10 & 8 & 2 & 2.4 & $\mathbf{V}$ \\
\hline $\begin{array}{l}\text { 14. Gathering the } \\
\text { feedback from the } \\
\text { audience }\end{array}$ & 10 & 8 & 2 & 2.4 & $\mathbf{V}$ \\
\hline 15. Stage etiquettes & 11 & 8 & 1 & 2.5 & IV \\
\hline $\begin{array}{l}\text { 16. Dressing for the } \\
\text { speech }\end{array}$ & 8 & 9 & 3 & 2.25 & VII \\
\hline
\end{tabular}

80 percent students have knowledge that rehearsal and early preparation prior to public speaking help to reduce blunders while delivering the content. Majority of students' i.e. 65 per cent students are well aware that technical issues (mike testing, audio recorder etc) should be handled carefully before speech presentation as its malfunctioning can 
degrade the efficiency of the speaker. Blunders which might hurt the socio-cultural beliefs of the audience should be avoided and 65 per cent students know to overcome the blunders. Two statements regarding effective non-verbal components and verbal components were not known by majority of the students i.e. $80-85$ per cent students. It was tried out to find the possible reasons behind it through FGD. It was found that students have not clear concept about different verbal and non-verbal components to be used in a speech and when to use it effectively, how to use it and with what frequency it should be repeated and when to pause it, these were the confusions in the mind of the students which create hindrances in the effective use of these components. Thus summer training might be organized on these aspects by the professor or professional experts of GBPUA\&T.

A perusal of Table 11 shows that majority of the respondents' i.e. 65 per cent students know the skill to select the purpose for which speech is being prepared. Further 60 per cent students divide the speech content effectively, are efficient to use the simpler words that could be easily understood by the target audience, have dressing sense as they prefer to wear light shade formal dress while speaking to the public and they smartly deal with the disagreements or arguments. 55 per cent students know how to make eye movements while speaking to the audience to emphasize on the topic of immediate concern.

Additionally, level of knowledge and attitude of audience are wisely analysed, facial expressions are properly made and the strategy to conclude are well performed by 50 per cent of the students. Furthermore, skill to organize the speech into different pattern such as chronological, spatial etc, students know the skill to integrate the supporting materials to provide a strong hierarchical base to the topic, effective timing of the gestures to be made are well known, indicators to gauge audience interest are used smartly and use of voice i.e. voice modulation is effectively done to improve the public speaking effectiveness by the 45 per cent students.

It was found that 35 percent of the students have skill to choose the best gesture for the moment, to sort out relevant material for the content and techniques to convert complex things into simpler forms for enhancing the level of understanding of the audience. Appropriate strategy to do presentation is known by only 30 per cent of the students.

The skills for the posture to be maintained while speaking, identification of audience profile was known to 25 per cent students. Preparation and organisation of the Content matter is an important task to be performed for public speaking is well known to only 15 per cent of the students. Further 10 per cent students us ideal pace of delivery and majority are not concerned about it.

The biggest lacuna was found that 95 per cent of the students are not proficient in selecting the topic on which speech is to be prepared. They are not able to decide whether they want their speech to be inspirational, persuasive, entertaining etc. Thus a need based training must be organized to make the students proficient in selecting the topic.

\section{Training Needs in Public Speaking}

It can be revealed from the Table12, use of verbal skills effectively $(M=2.75)$ was the most important training need since 75 per cent of the students opined it very much needed. Students feel that adjustment of pitch, voice modulation, effective articulations are required to make their public speaking more effective. Secondly they require training on organization and presentation of conclusion of speech $(\mathrm{M}=2.70)$ to have long lasting 
impression conclusion. They need to know what should be inculcated in conclusion and what should be not? Additionally, the members also desired to have training on boosting confidence and reducing the anxieties $(M=2.6)$ as stage fear is deeply penetrated in them, they don't have enough courage to face audience. Further, training on grabbing the attention of the audience $(\mathrm{M}=2.6)$, creating transitions between introduction, body and conclusion $(M=2.5)$, editing the content before finalizing $(\mathrm{M}=2.5)$, using non-verbal skills effectively $(\mathrm{M}=2.5)$, stage etiquettes $(M=2.5)$ gathering the data from different secondary sources using stories, examples in the content $(M=2.4)$ were required.

The least need was felt for dressing for the speech $(M=2.25)$ as many of them know to dress formally during public speaking.

Good presentation skills require organisation and confidence. Good public speaking skills are very important when looking for a job. Personality development through public speaking will really assist you to develop first more confidence, which is the key.to success. Thus help you getting organised, well presented and ultimately building self-esteem and thus those dream jobs will appear and your ambitions will be realized. Presentation skills and public speaking are a "learnt" skill - by working on these skills, the quiet and shy person can learn to present with confidence and evidentially "Find their voice","

\section{References}

Ayres, Joe. (1996). Speech preparation processes and speech apprehension. Communication Education, 45, 228-35.

Lizotte, K. (2008). The expert's edge: Become the go-to authority people turn to every time [Kindle 2 version]. New York, NY: McGraw-Hill. Retrieved from Amazon.com (locations 72-78).

Menzel, Kent E., and Carrell, Lori J. (1994). The relationship between preparation and performance in public speaking. Communication Education, 43, 17-26.

Noonan, Peggy. (1998). Simply speaking. New York: Regan Books.

Rose, H. M., and Rancer, A. S. (1993). The impact of basic courses in oral interpretation and public speaking on communication apprehension. Communication Reports, 6, 54-60.

\section{How to cite this article:}

Smriti Singh and Neha. 2019. A Study on Knowledge and Skill Level of Public Speaking for Employment among UG and PG Students of Gbpuat Pantnagar, Uttarakhand, India. Int.J.Curr.Microbiol.App.Sci. 8(07): 325-334. doi: https://doi.org/10.20546/ijcmas.2019.807.040 